\title{
Body Weight Gain Supplemental Qualifiers Dataset
}

National Cancer Institute

\section{Source}

National Cancer Institute. Body Weight Gain Supplemental Qualifiers Dataset. NCI

Thesaurus. Code C147188.

A dataset containing supplemental information, specifically non-standard variables, to parent records in the body weight gain domain. 